\title{
Self-reported cataracts in older adults in Ghana: sociodemographic and health related factors
}

\author{
Alfred E Yawson 1,2, Edith M Ackuaku-Dogbe ${ }^{3}$, Nana A Hagan Seneadza ${ }^{1,2}$, George Mensah ${ }^{1}$, Nadia Minicuci ${ }^{1,4}$, \\ Nirmala Naidoo ${ }^{5}$, Somnath Chatterji, ${ }^{5}$ Paul Kowal ${ }^{5,6}$ and Richard B Biritwum ${ }^{1}$
}

\begin{abstract}
Background: Changes in function of sensory organs with increasing age have significant impact on health and wellbeing of older persons. This paper describes cataract, a chronic eye condition, self-reported among older adults in Ghana and the need for improving access to eye care services.

Methods: This work was based on the World Health Organization's multi-country Study on global AGEing and adult health (SAGE), conducted in six countries including Ghana. SAGE Wave 1 in Ghana was conducted in 2007-2008 in a nationally representative sample of 4278 older adults, $\geq 50$ years. Data were obtained on sociodemographic and health factors related to self-reported cataracts in older persons in Ghana. Data were analysed using descriptive measures (frequencies and proportions), chi-square test for associations in categorical outcome measures, and logistic regression for predictors of cataracts with SPSS version 21.
\end{abstract}

Results: Overall prevalence of self-reported cataracts among 4278 older adults in Ghana was 5.4\%. Prevalence was proportionately higher for women (5.9\%) than men (4.7\%). Reported cataracts increased with age, among urban residents, in older adults living without partners and among those with the worse life satisfaction index. Older adults in lower income groups, poorly educated or living alone had difficulty seeking vision care services. Prevalence was $8.4 \%$ among persons with diabetes, $10.4 \%$ among hypertensives and $11.4 \%$ in persons with previous history of stroke. Among older persons who had ever used alcohol or tobacco, prevalence rates of reported cataracts were $5.7 \%$ and $4.9 \%$, respectively. Logistic regression analysis indicated that increasing age, lower income status and self-reported hypertension were significantly associated with cataract among older adults in Ghana.

Conclusions: Cataract is prevalent in older people in Ghana with approximately 1 in 20 people aged 50 years or older reporting a previous diagnosis of cataract. As cataract surgery is restorative, a public health approach on behavioural modification, well structured national outreach eye care services (for rural residents), inclusion of basic eye health services at sub-district levels, increased family support and national health insurance for older persons is indicated.

Keywords: Older adult, Cataracts, Eye care service, Subjective wellbeing, Ghana, Low income countries

\section{Background}

Cataract is the leading cause of blindness accounting for nearly $48 \%$ of blindness globally $[1,2]$. It poses a substantial economic and public health burden especially in developing countries. According to a World Health Organization (WHO) report on global blindness, approximately $90 \%$ of global cataract is seen in developing

\footnotetext{
* Correspondence: aeyawson@yahoo.com

'Department of Community Health, University of Ghana Medical School, College of Health Sciences, Room 46, Korle-Bu, P.O. Box 4236, Accra, Ghana

${ }^{2}$ Public Health Unit, Korle-Bu Teaching Hospital, Korle-Bu, Accra, Ghana

Full list of author information is available at the end of the article
}

countries and estimates that more than $82 \%$ of all blindness occurs in individuals aged 50 and older [2].

In a population based study in Ghana, the prevalence rates of cataract causing low vision or blindness in people aged 40 years and above was $9 \%$ in the Volta region [3] and 2\% in people aged 30 years and above in the Wenchi area of the Brong Ahafo region [4], two of the ten regions in Ghana. The burden of cataracts is not limited to financial costs to society alone, older persons living with un-operated cataracts are likely to have sig- 
nificantly reduced quality of life due to low vision. Other co-morbid conditions in older persons further reduces their quality of life. Decreases in functional abilities may be attributed to other age-related processes but may actually be associated with the onset of cataract.

Some health, lifestyle and environmental conditions have been associated with the development of cataracts. Research has strongly associated diabetes, smoking and ultra violet light exposure with the development of age related cataract [5-9]. Other factors inconclusively implicated in the development of cataracts include body mass index $[10,11]$ and post menopausal decline in estrogen [12].

Aging is often accompanied by the cumulative impact of chronic disease, increased prevalence of disability, worsening health status and reduced quality of life among the growing number of older persons. Aging, in itself, has been associated with a decline in visual functioning, with associated decline in physical and mental functioning. A number of studies have demonstrated impact of cataract related visual impairment on quality of life $[13,14]$. These studies, showed that worsening of general functioning, psychosocial and overall eyesight were associated with increased visual loss. Those with increased visual loss were more likely to report dissatisfaction with quality of life and had poorer self-rated health than persons with normal vision.

In addition, smoking, body-mass index, and exercise patterns in midlife and late adulthood have been suggested as predictors of disability in later years. For the average person, efforts to reduce modifiable health risks may result in a postponement of initial disability and decreased lifetime disability [15].

Current eye health services in Ghana are organized at three levels, national, regional and district [16]. The national and regional levels provide specialized eye care services through the teaching and regional hospitals. Basic eye health services at the district is provided through district hospitals by ophthalmic nurses (i.e. state registered general nurses who have additional training in ophthalmology). Unlike the general health delivery system with structures to provide health care at sub-district and community level [16], eye health services is limited to the district level. Sub-districts and communities (where most of the rural population reside) receive eye care services through outreach programmes and special mobile eye clinics.

The goal of this analysis is to describe the sociodemographic, health related factors and life satisfaction index in older adults with self-reported cataract in Ghana. It is aimed at providing guidance for national plans on eye care for older persons and to contribute to national policy on interventions to mitigate health related factors in the older adult population.

\section{Methods}

SAGE Wave 1 was undertaken in Ghana in a partnership between the University of Ghana's Department of Community Health, the Ministry of Health and WHO, as part of a multi-country longitudinal study to complement existing aging data sources and to inform policy and programmes $[17,18]$. A nationally representative sample of respondents $\geq 50$ years were interviewed on sociodemographic background, health risk factors, chronic conditions, well-being and health insurance coverage. Face-to-face interviews and data entry were undertaken between May 2007 and June 2008. Ethical approval for SAGE Wave 1 in Ghana was given by WHO's Ethical Review Board and the University of Ghana Medical School Ethics and Protocol Review Committee. All study participants provided informed consent $[17,18]$.

\section{Measures}

Demographic and socioeconomic variables included sex, age, marital status, highest educational level completed, health insurance status and household income levels. Access to health care in Ghana is through the National Health Insurance Scheme (NHIS), introduced in 2003 and operationalized in most public and private health facilities in 2005. Basic eye care services including cataract surgery is covered by the NHIS. Assessment of health insurance status of older persons was based on this[19]. Educational level was categorized as low (primary or basic school completed or less) and high (at least secondary school completed or higher).

\section{Chronic diseases}

SAGE collected data on prevalent chronic diseases in older persons in Ghana. Data on four of these chronic conditions (cataract, diabetes mellitus, hypertension and stroke) were used in this analysis. For cataract, the question asked was: "In the last 5 years, were you diagnosed with a cataract in one or both of your eyes (a cloudiness in the lens of the eye) by a health care professional?" Diagnosis of cataract in Ghana is done by a doctor or nurse trained in ophthalmology. SAGE Wave 1 in Ghana included operated and unoperated cataract within the self-reported diagnosis of cataract in the last 5 years.

The prevalence rates for the other chronic diseases were obtained through responses to the question "Has a health care professional ever told you, you have...?". Though SAGE Wave 1 measured blood pressure, the analysis considered only self-reported hypertension due to the focus on self-reported ill-health among older persons in Ghana $[17,18]$.

\section{Tobacco use}

Lifetime tobacco use was assessed with the question 'Have you ever smoked tobacco or used smokeless tobacco?' 
SAGE considered tobacco products such as cigarettes, cigars, pipes, chewing tobacco, or snuff. Details on how tobacco use was assessed is provided in published elsewhere $[17,18,20]$.

\section{Alcohol use}

Lifetime alcohol use was assessed from responses to the question 'Have you ever consumed a drink that contains alcohol (such as beer, wine, spirits, etc.)?' SAGE Wave 1 quantified alcohol (commercially available and homebrewed beverages) in "standard drink" units as recommended by the World Health Organization $[17,18,20]$.

\section{Body mass index (BMI)}

Was obtained from measured weight and height of respondents.

\section{Subjective wellbeing (SWB)}

Well-being or life satisfaction was assessed through a multi-dimensional scale, the WHO Disability Assessment Schedule 2.0, including a question about satisfaction with life overall $[17,18]$. SWB as a single item measure was based on the overall life satisfaction question. As in a similar analysis by Yawson et al., 2013, the responses to this question were categorized into satisfied (very satisfied and satisfied), indifferent (neither satisfied nor dissatisfied) and not satisfied (dissatisfied and very dissatisfied) [21].

\section{Wealth or income quintiles}

Were derived from the household ownership of durable goods, dwelling characteristics and access to services (improved water, sanitation and cooking fuel) for a total of 21 assets. Wealth levels were generated through a multi-step process, where asset ownership was converted to an asset ladder, Bayesian post-estimation method used to generate raw continuous income estimates, and then income transformed into quintiles $[17,18,20]$.

\section{Data analysis}

Demographic and socio-economic variables such as age, location (urban/ rural), educational level, marital status (due to its relevance in social support and health access), and income levels were described using proportions. Chisquare tests of significance were used to compare distribution of cataract and demographic, socioeconomic, health risk and life satisfaction indices.

Binary logistic regression analysis was done to determine factors associated with cataract in the older persons. Ever been diagnosed with cataract was the binary dependent variable in the regression model. Independent variables used included age, sex, location (urban/rural), educational level, marital status, income quintile, health insurance status, self-reported chronic conditions (diabetes, hypertension and stroke), alcohol use, tobacco use, and subjective wellbeing. Decisions were based on adjusted odds ratio $[A O R]$ and p-values at $95 \%$ confidence level. Data were analysed using SPSS version 21.

\section{Results}

Overall prevalence of cataracts in the 4278 older adults in Ghana was $5.4 \%$. Prevalence was proportionately higher in women $(5.9 \%)$ than men (4.7\%); though this difference was not statistically significant $(p$-value $=0.067)$. The prevalence of cataract clearly showed an age gradient: higher values were reported in the older age groups (from $2.1 \%$ in $50-59$ age group to $9.5 \%$ in $\geq 70$ years). Age differences in prevalence of cataract was statistically significant $(\mathrm{p}$-value $=0.001)$. Urban residents reported statistically significant higher rates (6.6\%) than rural residents (4.4\%). Older adults living without a partner (separated/divorced/ widowed) reported significantly higher prevalence of cataract (6.6\%), compared to those living with a partner (married/cohabiting) (4.3\%) as shown in Table 1. Older adults with secondary school education or higher, had a higher prevalence compared to those with primary school completed or less. Older adults in high income groups (Q4 and Q5) reported significantly higher levels of cataract (6.6\%) compared to those within low income group (Q1 and Q2) (4.3\%). Interestingly, older adults on national health insurance reported significantly higher prevalence of cataract (7.1\%) than those without insurance (4.2\%).

As demonstrated in Table 2, prevalence of cataract among obese older adults was $5.8 \%$. Among older adults with self-reported chronic non-communicable conditions, prevalence was $8.4 \%$ among those with diabetes, $10.4 \%$ among hypertensives and $11.4 \%$ in those with previous history of stroke. The prevalence of cataract among older adults who had ever used alcohol was 5.7\%. Interestingly, older persons who had used tobacco had a lower prevalence of self-reported cataract (4.9\%) compared to those who had never used tobacco.

Analysis of satisfaction with daily living among older adults found the highest prevalence of cataract among those who expressed dissatisfaction with life (9.9\%) and the lowest prevalence (4.7\%) among those satisfied with life.

\section{Important associated factors of cataract in older adults in Ghana}

Logistic regression analysis indicated that increasing age, income status and self-reported hypertension were factors significantly associated with cataract among older adults in Ghana as in Table 3. With increasing age, the risk of cataract was highest in 60-69 years $(A O R=7.8$, CI 4.424-13.684), and slightly higher in the $\geq 70$ years $(\mathrm{AOR}=2.5$, CI 1.551- 4.125) compared to older adults 50-59 years. High income (Q4 and Q5) was shown to 
Table 1 Prevalence of self-reported cataracts in older adults in Ghana by demographic and socioeconomic characteristics, SAGE Wave 1

\begin{tabular}{|c|c|c|c|}
\hline \multirow[t]{2}{*}{ Characteristics } & \multicolumn{2}{|c|}{$\begin{array}{l}\text { Self reported } \\
\text { cataract }\end{array}$} & \multirow[t]{2}{*}{$x^{2}$ (p-value) } \\
\hline & n (\%) & $\mathbf{N}$ & \\
\hline \multicolumn{4}{|l|}{ Sex } \\
\hline Male & $106(4.7)$ & 2249 & $3.35(0.067)$ \\
\hline Female & $120(5.9)$ & 2029 & \\
\hline \multicolumn{4}{|l|}{ Age group } \\
\hline $50-59$ & $35(2.1)$ & 1681 & \\
\hline $60-69$ & $59(4.9)$ & 1196 & $83.88(0.001)$ \\
\hline $70+$ & $133(9.5)$ & 1401 & \\
\hline \multicolumn{4}{|l|}{ Residence } \\
\hline Urban & $115(6.6)$ & 1749 & $9.46(0.002)$ \\
\hline Rural & $111(4.4)$ & 2529 & \\
\hline \multicolumn{4}{|l|}{ Marital status } \\
\hline Never married & $4(8)$ & 54 & \\
\hline $\begin{array}{l}\text { Living with partner } \\
\text { (married/cohabiting) }\end{array}$ & $104(4.3)$ & 2426 & $11.92(0.003)$ \\
\hline $\begin{array}{l}\text { Living without partner } \\
\text { (Separated/divorced/Widowed) }\end{array}$ & $119(6.6)$ & 1798 & \\
\hline \multicolumn{4}{|l|}{ Highest educational level } \\
\hline Primary school completed or less & $162(5.2)$ & 3114 & $0.229(0.632)$ \\
\hline Secondary school and above & $66(5.7)$ & 1164 & \\
\hline \multicolumn{4}{|l|}{ Income quintile } \\
\hline Q1 and Q2 (low) & $105(4.3)$ & 2441 & \\
\hline Q3 (middle) & $2(5.7)$ & 39 & $10.71(0.005)$ \\
\hline Q4 and Q5 (high) & $119(6.6)$ & 1798 & \\
\hline \multicolumn{4}{|l|}{ Health insurance } \\
\hline Yes & $116(7.1)$ & 1638 & $16.58(0.001)$ \\
\hline No & $111(4.2)$ & 2640 & \\
\hline Total respondents & $231(5.4)$ & 4278 & \\
\hline
\end{tabular}

be associated with a lower risk for self-reported cataract $(\mathrm{AOR}=0.6$, CI 0.415-0.983 ) compared to the low income group (Q1 and Q2). Older adults who did not selfreport hypertension had lower risk for self-reported cataract $(\mathrm{AOR}=0.4$, CI 0.248-0.625).

\section{Discussion}

Cataract is one of the major conditions chosen by the global initiative, Vision 2020-The Right to Sight, due to the magnitude of its contribution to the burden of blindness [22]. Several studies which focused on the burden of visual loss from cataracts demonstrate the prevalence of cataracts increases with increasing age and is slightly higher among women [23-25]. Our study confirms the findings from these studies.
Table 2 Prevalence of self-reported cataracts in older adults in Ghana by health related factors and subjective wellbeing, SAGE Wave 1

\begin{tabular}{llll}
\hline Characteristics & \multicolumn{2}{c}{ Self reported cataract } & \multirow{2}{*}{$X^{2}$ (p-value) } \\
\cline { 2 - 3 } & $\mathrm{n}(\%)$ & $\mathrm{N}$ & \\
\hline
\end{tabular}

\section{Obese}

Yes

No

$\begin{array}{ccc}26(5.8) & 449 & 0.42(0.519) \\ 195(5.1) & 3829 & \end{array}$

Self-reported diabetes

$\begin{array}{lllll}\text { Yes } & 14(8.4) & 162 & 3.31(0.069)\end{array}$

No

$214(5.2) \quad 4116$

Self-reported hypertension

Yes $\quad 60(10.4) \quad 580 \quad 35.63(0.001)$

No

$166(4.5) \quad 3698$

Self-reported stroke

$\begin{array}{llll}\text { Yes } & 12(11.4) & 108 & 8.74(0.003)\end{array}$

No

$213(5.1) \quad 4170$

Alcohol use

Ever

$143(5.7) \quad 2512$

$0.001(0.976)$

Never

$93(5.3) \quad 1766$

Tobacco use

Ever

$54(4.9) \quad 1111$

$0.395(0.530)$

Never

$171(5.4) \quad 3167$

Level of subjective well being/life satisfaction

\begin{tabular}{lccc} 
Satisfied & $113(4.7)$ & 2407 & \\
Indifferent & $105(5.8)$ & 1799 & $5.76(0.056)$ \\
Not satisfied & $7(9.9)$ & 72 & \\
\hline
\end{tabular}

An appreciation of the impact of visual impairment or blindness on one's functional ability and quality of life is useful in providing a comprehensive picture of the burden of visual impairment beyond clinical evaluation [26]. In addition, other non-communicable and chronic diseases currently accounting for $60 \%$ of deaths globally per annum and $47 \%$ of the global burden of disease [27] are mostly associated with aging. The frequency of these conditions increases with age, and they do occur concurrently with cataract as shown in this and other studies $[28,29]$.

Prevalence of cataract among older persons was determined through a question on whether they have been told by a health professional that they have cataract. In the health delivery system of Ghana, these health professional are either doctors or ophthalmic nurses with capacity to diagnose basic eye conditions including cataracts [16]. The observation suggests that those diagnosed might have accessed eye care services at health facilities or during screening programs. Thus increased prevalence may imply improved access to health care and not necessarily increased disease burden. The prevalence of cataract in this group of people (5.4\%) is lower than that 
Table 3 Factors associated with self-reported cataract in older adults in Ghana, SAGE Wave 1

\begin{tabular}{|c|c|c|c|c|}
\hline \multirow{2}{*}{ Characteristic } & \multirow{2}{*}{ Odds ratio } & \multicolumn{2}{|c|}{ 95\% Confidence interval } & \multirow{2}{*}{ P-value } \\
\hline & & Lower & Upper & \\
\hline \multicolumn{5}{|l|}{ Sex } \\
\hline Male & - & & & \\
\hline Female & 1.364 & 0.77 & 2.42 & 0.287 \\
\hline \multicolumn{5}{|l|}{ Location } \\
\hline Urban & - & & & \\
\hline Rural & .926 & 0.59 & 1.44 & 0.733 \\
\hline \multicolumn{5}{|l|}{ Age group } \\
\hline $50-59$ years & - & & & \\
\hline $60-69$ years & 7.781 & 4.42 & 13.68 & 0.001 \\
\hline 70 years and above & 2.530 & 1.55 & 4.13 & 0.001 \\
\hline \multicolumn{5}{|l|}{ Educational level } \\
\hline Primary completed or less & - & & & \\
\hline Secondary or higher & 1.371 & 0.88 & 2.14 & 0.164 \\
\hline \multicolumn{5}{|l|}{ Marital status } \\
\hline Never married & - & & & \\
\hline \multicolumn{5}{|l|}{ Living with partner (currently married } \\
\hline and cohabiting) & 0.190 & 0.02 & 1.76 & 0.143 \\
\hline Living without partner (separated/divorced and widowed) & 0.467 & 0.10 & 2.19 & 0.334 \\
\hline \multicolumn{5}{|l|}{ Income status } \\
\hline Low income level (Q1 and Q2) & - & & & \\
\hline Middle income level (Q3) & 2.502 & 0.55 & 11.41 & 0.236 \\
\hline Higher income level (Q4 and Q5) & 0.639 & 0.42 & 0.98 & 0.042 \\
\hline \multicolumn{5}{|l|}{ Self-reported Stroke } \\
\hline No & - & & & \\
\hline Yes & 1.124 & 0.38 & 2.00 & 0.754 \\
\hline \multicolumn{5}{|l|}{ Self-reported Diabetes } \\
\hline Yes & - & & & \\
\hline No & 1.169 & 0.52 & 2.61 & 0.703 \\
\hline \multicolumn{5}{|l|}{ Self-reported hypertension } \\
\hline Yes & - & & & \\
\hline No & 0.394 & 0.25 & 0.63 & 0.001 \\
\hline \multicolumn{5}{|l|}{ Lifetime Tobacco use } \\
\hline Ever & - & & & \\
\hline Never & 1.187 & 0.68 & 2.06 & 0.543 \\
\hline \multicolumn{5}{|l|}{ Lifetime alcohol } \\
\hline \multicolumn{5}{|l|}{ Ever } \\
\hline Never & 0.879 & 0.55 & 1.40 & 0.587 \\
\hline \multicolumn{5}{|l|}{ Level of subjective well being/life satisfaction } \\
\hline Satisfied & - & & & \\
\hline Indifferent & .381 & .046 & 3.14 & 0.370 \\
\hline Dissatisfied & .328 & .040 & 2.70 & 0.299 \\
\hline
\end{tabular}


reported in the cataract prevalence study among those 40 years and older in the Volta region, one of the ten regions in Ghana (9\%) [3]. These differences may be as a result of the differences in the study design, the earlier studies were based on population screening and limited to cataract causing low vision or blindness. In this analysis most cases of cataracts (of any degree of maturity), were more likely to have been diagnosed by trained health professionals at the health facility; hence the relatively higher prevalence in the earlier studies.

Urban residents reported statistically significant higher rates $(6.6 \%)$ than rural residents $(4.4 \%)$. This may be related to better access to eye health care with aggregation of eye care services in urban areas in Ghana. Rural areas have limited access and residents depend mainly on erratic outreach services for eye health care. Most rural residents access health care at sub-district levels (health centres and community-based health care) where routine eye care services are unavailable. In addition overall cataract surgical uptake among older persons in Ghana from the national report on SAGE wave 1 was $48.9 \%$ [17]. Access to eye care services is critical for early risk detection and prevention of blindness or visual impairment. Well structured outreach eye care services for rural residents or inclusion of basic eye health services at sub-district levels is critical to improve eye health of older persons in Ghana.

Older adults living without a partner (separated/ divorced/ widowed) reported significant higher prevalence of cataract (6.6\%), compared to those with a partner (married/cohabiting) (4.3\%). It may imply this group of older persons might have assessed health care previously and been diagnosed or that older persons living alone are less likely to access health care services; thus the relative higher prevalence of cataract. This may be related to other social support factors; the older adult with visual disability may have multiple disabilities as well [29]. These older adult would need more assistance (physical, social and economic) to access eye care services and living alone may limit the availability of this assistance.

Persons with higher education, higher income and health insurance reported significant higher prevalence of cataract. A potential explanation is their ability to access eye care services due to better knowledge on availability of these services, ability to afford other personal costs involved in seeking health care and improved financial access to health care through the national health insurance scheme. Older adults with low educational background on the other hand may not attach much importance to seeking early and appropriate eye care services. The fifth round of the Ghana living standards survey report in 2008 showed that $31 \%$ of all adults had never been to school, less than one-fifth (17\%) attended school but did not obtain any qualifications; while a small percentage of $14 \%$ possessed secondary or higher qualification [30]. Improving the literacy level of Ghanaians is likely to encourage self-reporting to medical facilities for early diagnosis and treatment.

Generally, in this analysis, older persons in low income groups, poorly educated or living alone had some difficulty seeking vision services and care to prevent blindness or visual impairment. This constitute a vulnerable group who may require special attention to access eye care services. Social protection strategies including enrolment of older adults freely on the national health insurance scheme (NHIS) should be a national health policy worth considering. Currently only older persons $\geq 70$ years are eligible for free enrolment on the NHIS [31].

Analysis also demonstrated that prevalence of selfreported cataract was relatively higher in older persons with health related factors such as obesity, diabetes, hypertension, previous history of stroke and alcohol use. Prevalence of cataract in persons with obesity, diabetes, hypertension, previous history of stroke were $5.1 \%, 8.4 \%$, $10.4 \%$ and $11.4 \%$ respectively. Among older persons who had ever used alcohol or tobacco, the prevalence was $5.7 \%$ and $4.9 \%$ respectively. These findings agree with those in other studies that found similar associations $[23,24]$. An interesting observation however, was that older persons who had used tobacco had relatively lower prevalence of self-reported cataract. The authors suggest a more detailed study to determine possible factors that may account for this.

A public health approach on behavioural modification (for modifiable and preventable risks- obesity, alcohol consumption and tobacco use) may be required to improve the eye health of older persons in Ghana. Diabetes is recognized as a significant risk factor due to it metabolic effect on the crystalline lens [32,33]; disease specific health prevention efforts at national and local levels is imperative.

Analysis on satisfaction with daily living among older persons indicate prevalence of cataract is highest among the few older persons who expressed dissatisfaction with life (9.9\%) and is lowest (4.7\%) among those satisfied with life. Studies among older persons in communities, identified hearing and visual impairments as important factors that lead to functional decline and increased morbidity (imbalance, hip fracture, and depression) as well as mortality [29]. In addition, visual loss in older adults poses significant challenges for families who have to support them; existence of such social support for older persons in communities is often lacking [29].

In Bangladesh, Polack and others in 2008 [27] found that cataract related visual impairment negatively affected perceived health and well-being, beyond vision-specific experience. Also worsening general functioning, psychosocial 
and overall eyesight scores were found to be associated with increased visual loss. In their study, those with selfreported cataract significantly reported more problems with mobility, self-care, activities of daily living, pain and depression/anxiety and had significantly poorer mean selfrated health. Influence of cataract on the health and social wellbeing of individuals have also been demonstrated in studies from Kenya [14] and India [13].

\section{Limitation}

Calling other binding diseases as cataract, and labelling any ocular/orbital/adnexal surgical procedures as cataract surgery by the older adults are very likely. The SAGE Wave 1 relied on individual submissions and did not objectively confirm cataract diagnosis or cataract surgery. The self-report of health conditions, (such as cataract and hypertension), is likely to result in underestimation of prevalence rates compared to measured rates [34]. The analysis however, provides information on prevalence of self-reported cataract among older persons across the regions of Ghana as a baseline for further investigations.

\section{Conclusion}

Prevalence of cataract increased significantly with increasing age, was slightly higher among women, urban residents and older adults living without a partner. Significantly higher prevalence of self-reported cataract were observed in older persons with higher education, higher income and health insurance (due probably to better access to eye health care). Those who were poorly educated and with low incomes had some difficulty seeking vision services and care to prevent blindness or visual impairment.

Risk modification through effective primary prevention and health promotion efforts; behavioural modification, including public health campaigns are key efforts to limit the burden of cataract among older persons in Ghana. Well structured national outreach eye care services for rural residents and inclusion of basic eye health services at sub-district health levels of Ghana's primary health care structure are needed. Increased family support and national social protection strategies (including enrolment of older adults on national health insurance scheme) linked to the national aging policy will improve access to eye health care.

\section{Competing interests}

The authors declare that they have no competing interest. The views expressed in this paper are those of the authors. No official endorsement by the World Health Organization or Ministry of Health of Ghana/Ghana Health Service is intended or should be inferred.

\section{Authors' contributions}

AE Yawson and EM Ackuaku-Dogbe developed the concept, AE Yawson, G Mensah, N Minicuci, N Naidoo, S Chatterji, P Kowal and RB Biritwum are members of the WHO Multi-country SAGE Study Team involved in the conduct and analysis of the SAGE survey in Ghana. NA Hagan Seneadza, EM
Ackuaku-Dogbe and AE Yawson contributed to the writing and reviewing of the various sections of the manuscript. All the authors reviewed the final version of the manuscript before submission. All authors read and approved the final manuscript.

\section{Authors' information}

Yawson AE, Mensah G, MinicuciN and Biritwum RB are members of the WHO Multi-country SAGE Team who conducted the SAGE Survey in Ghana. Naidoo $\mathrm{N}$, Chatterji S and Kowal P are members of the WHO Multi-country SAGE Team and coordinators of the multi-country study at the WHO Headquarters in Geneva. EM Ackuaku-Dogbe is a Consultant Ophthalmologist of the University of Ghana Medical School and NA Hagan Seneadza is a Specialist Public Health Physician of the Korle-Bu Teaching Hospital.

\section{Acknowledgement}

We are grateful to all respondents and interviewers who made the SAGE survey in Ghana possible. Financial support was provided by the US National Institute on Aging through Interagency Agreements (OGHA 04034785; YA1323-08-CN-0020; Y1-AG-1005-01) with the World Health Organization and a Research Project Grant (R01 AG034479-64401A1). WHO contributed financial and human resources to SAGE. The Ministry of Health, Ghana, is supportive of SAGE.

The Department of Community Health of University of Ghana Medical School contributed training facilities, data entry support, and storage of materials. The Ghana Statistical Office provided the sampling information for the sampling frame and updates.

\section{Author details}

${ }^{1}$ Department of Community Health, University of Ghana Medical School College of Health Sciences, Room 46, Korle-Bu, P.O. Box 4236, Accra, Ghana. ${ }^{2}$ Public Health Unit, Korle-Bu Teaching Hospital, Korle-Bu, Accra, Ghana. ${ }^{3}$ Department of Surgery, Eye Unit, University of Ghana Medical School, College of Health Sciences, Korle-Bu, Accra, Ghana. ${ }^{4}$ National Council Research, Institute of Neuroscience, Padova, Italy. ${ }^{5}$ World Health Organization, Multi-Country Studies unit, Geneva, Switzerland. 'University of Newcastle Research Centre on Gender, Health and Aging, Newcastle, Australia.

Received: 20 October 2013 Accepted: 9 September 2014

Published: 12 September 2014

\section{References}

1. World Health Organization: Global Data on Visual Impairments 2010. Geneva, Switzerland: Published by the World Health Organization; 2012. WHO/NMH/ PBD/12.01 (http://www.who.int/about/regions/en/index.html).

2. Resnikoff $S$, Pascolini D, Etya'ale D: Global data on visual impairment in the year 2002. Bull World Health Organ 2004, 82:844-851.

3. Guzek JP, Anyomi FK, Fiadoyor S, Nyonator F: Prevalence of blindness in people over 40 years in the volta region of Ghana. Ghana Med J 2005, 39(2):52-62

4. Moll AC, Van der Linder AJH, Hogeweg M, Schader WE, Hermans J, De K: Prevalence of blindness and low vision of people over 30 years in the Wenchi district, Ghana, in relation to eye care programmes. BJO 1994, 78:275-279.

5. West SK, Valmadrid CT: Epidemiology of risk factors for age-related cataract. Surv Ophthalmol 1995, 39:323-324.

6. McCarty CA, Taylor HR: A review of the epidemiologic evidence linking ultraviolet radiation and cataracts. Dev Ophthalmol 2002, 35:21-31.

7. Hodge WG, Whitcher JP, Satariano W: Risk factors for age-related cataracts. Epidemiol Rev 1995, 17:336-346.

8. Taylor HR: Epidemiology of age-related cataract. Eye 1999, 13(Pt 3b):445-448.

9. DeBlack SS: Cigarette smoking as a risk factor for cataract and agerelated macular degeneration: a review of the literature. Optometry 2003, 74(2):99-110.

10. Jacques PF, Moeller SM, Hankinson SE: Weight status, abdominal adiposity, diabetes, and early age-related lens opacities. Am J Clin Nutr 2003, 78:400-405.

11. Glynn R, Christen W, Manson JE: Body mass index: an independent predictor of cataract. Arch Ophthalmol 1995, 113:1131-1137.

12. Hennis A, Wu SY, Nemesure B: Risk factors for incident cortical and posterior subcapsular lens opacities in the Barbados Eye Studies. Arch Ophthalmol 2004, 122:525-530. 
13. Nirmalan PK, Tielsch JM, Katz J: Relationship between vision impairment and eye disease to vision-specific quality of life and function in rural India: the Aravind Comprehensive Eye Survey. Invest Ophthalmol Vis Sci 2005, 46:2308-2312.

14. Polack S, Kuper $H$, Mathenge W: Cataract visual impairment and quality of life in a Kenyan population. Br J Ophthalmol 2007, 91:927-932.

15. Vita AJ, Richard B, Terry HB, Hubert D, James F: Aging, health risks, and cumulative disability. New Engl J Med 1998, 3(15):38-42.

16. Ghana Health Service Annual Report: Annual report of the Ghana Health Service, 2012. Accra, Ghana: Published by the Ghana Health Service; 2013.

17. Department of Community Health, University of Ghana Medical School: Ghana National Report on World Health Organization's Study on global AGEing and adult health (SAGE) in Ghana, Wave 1. Geneva: WHO; 2012.

18. Kowal P, Chatterji S, Naidoo N, Biritwum R, Wu F, Lopez Ridaura R, Maximova T, Arokiasamy P, Phaswana-Mafuya N, Williams S, Snodgrass JJ, Minicuci N, D'Este C, Peltzer K, Boerma JT, SAGE Collaborators: Data resource profile: the world health organization study on global AGEing and adult health (SAGE). Int J Epidemiol 2012, 1-11. doi:10.1093/ije/dys210

19. National Health Insurance Authority, Ghana: Annual report of the national health insurance scheme of Ghana (2010). Ghana: Published by the National Health Insurance Authority (NHIA); 2011.

20. Biritwum RB, Mensah G, Minicuci N, Yawson AE, Naidoo N, Chatterji S, Kowal $P$ : Study on global AGEing and adult health in Ghana: Methodology and household characteristics in Wave 1. Glob Health Action 2013, 6:20096. http://dx.doi.org/10.3402/gha.v6i0.20096.

21. Yawson AE, Baddoo A, Hagan-Seneadza NA, Calys-Tagoe B, Hewlett S, Dako-Gyeke P, Mensah G, Minicuci N, Naidoo N, Chatterji S, Kowal P, Biritwum R: Tobacco use in older adults in Ghana: sociodemographic characteristics, health risks and subjective wellbeing. BMC Pub Health 2013, 13:979. 10.1186/1471-2458-13-979.

22. WHO Library Cataloguing-in-Publication Data: Global Initiative for the Elimination of Avoidable Blindness. World Health Organization, Geneva, Switzerland: action plan; 2007:2006-2011.

23. Tsai SY, Hsu WM, Cheng CY, Liu JH, Chou P: Epidemiologic study of age-related cataracts among an elderly Chinese population in Shih-Pai, Taiwan. Ophthalmology 2003, 110(6):1089-1095.

24. Mukesh BN, Le A, Dimitrov PN, Ahmed S, Taylor HR, McCarty CA: Development of cataract and associated risk factors: the Visual Impairment Project. Arch Ophthalmol 2006, 124(1):79-85.

25. Currat $L$, de Francisco A, Al-Tuwaijri S, Al-Tuwaijri A, Jupp S, Global Forum for Health Research: Helping correct the 10/90 gap. The 10/90 Report on Health Research 2003-2004. Geneva, Switzerland: Published by Global Forum for Health Research; 2004.

26. World Health Organization: Global strategy on diet, physical activity and health. Geneva: Published by the World Health Organization; 2004

27. Polack S, Kuper H, Wadud Z, Fletcher A, Foster A: Quality of life and visual impairment from cataract in Satkhira district, Bangladesh. Br J Ophthalmol 2008, 92:1026-1030.

28. Adamson J, Lawlor DA, Ebrahim S: Chronic disease, locomotor activity limitation and social participation in older women: Cross sectional survey of British Women's Heart and Health Study. Age Ageing 2004, 33(3):293-298.

29. LaForge RG, Spector WD, Sternberg J: The relationship of vision and hearing impairment to one-year mortality and functional decline. J Aging Health 1992, 4:126-148.

30. Ghana Statistical Service: Ghana Living Standards Survey Report of the Fifth Round, [September 2005- September 2006]. Accra: Ghana Statistical Service; 2008.

31. National Health Insurance Authority, Ghana: Ghana National Health Insurance Act 650 of the Republic of Ghana. Accra, Ghana: Published by the Ghana Assembly Press; 2003.

32. Ederer F, Hiller R, Taylor HR: Senile lens changes and diabetes in two population studies. Am J Ophthalmol 1981, 91(3):381-395.
33. Janghorbani M, Jones RB, Allison SP: Incidence of and risk factors for cataract among diabetes clinic attenders. Ophthalmic Epidemiol 2000, $7(1): 13-25$.

34. Andresen E, Malmstrom TK, Miller DK, Miller JP, Wolinsky FD: Retest reliability of self-reported function, self-care and disease history. Med Care 2005, 43(1):93-97.

doi:10.1186/1471-2458-14-949

Cite this article as: Yawson et al:: Self-reported cataracts in older adults in Ghana: sociodemographic and health related factors. BMC Public Health 2014 14:949.

\section{Submit your next manuscript to BioMed Central and take full advantage of:}

- Convenient online submission

- Thorough peer review

- No space constraints or color figure charges

- Immediate publication on acceptance

- Inclusion in PubMed, CAS, Scopus and Google Scholar

- Research which is freely available for redistribution 